\title{
Quercetin-mediated 3-D hierarchical BiOI-Q and BiOI-Q-Ag nanostructures with enhanced photodegradation efficiency
}

\begin{abstract}
The nanostructured BiOI-Ag composite was successfully synthesized by quercetin-mediated hydrolysis method under varying $\mathrm{Ag}^{+}$amounts. The morphologies, phase structures, optical properties and certain other characteristics of the samples were examined under microscopic and spectroscopic investigations. The results revealed that the Ag nanoparticles were effectively grown on the BiOI nanoflowers, and a higher density was observed with increasing amount of $\mathrm{Ag}^{+}$. In addition, quercetin provided high stability and effectively controlled the size of the composites, and it also assisted in the formation of multiple heterojunctions, which triggered effective charge transference and higher separating efficiency of the photoinduced charges. Moreover, the photocatalytic activities of the as-synthesized BiOI-Ag(1), BiOI-Ag(2), and BiOI-Ag (3) samples were observed for the methyl orange disintegration (MO) and antibacterial activity against four different bacteria i.e. S. aureus, P. burmani, pseuodomonas, and P, aurgesa under visible light irradiation. The BiOI-Ag composites exhibited much higher photocatalytic efficacy over BiOI, and the optimized ratio was obtained to be BiOI-Ag (2). Moreover, the three photoinduced active species i.e. $\mathrm{h}^{+},{ }^{*} \mathrm{OH}$, and ${ }^{*} \mathrm{O}_{2}{ }^{-}$were the dominant active species in the photodisintegration process, and the stability of BiOI-Ag composites was observed for the cycling experiments.
\end{abstract}

\section{Introduction}

In the recent years, the visible-light-driven photocatalysts have been studied broadly because of their tremendous success in the environmental remediation [1-3]. Until now, $\mathrm{TiO}_{2}$ has been used extensively for the decontamination of toxic pollutants because of its chemical stability and catalytic activity. However, because of its large band gap of $3.2 \mathrm{eV}$, it is UV-light responsive which constitutes less than $5 \%$ of the total solar radiations [4-7]. Therefore, functionalization of $\mathrm{TiO}_{2}$ has been implemented with various other semiconductors such as, transition metal/nonmetals [8-11], narrow band gap semiconductors [12,13], and dye-sensitizers [14, 15] etc. Despite, major failures were observed such as residual toxicity, instability, and self photodegradation. 
Therefore, visible-light-driven photocatalysts offers an immense potential in the optimum utilization of the natural sunlight. Bismuth oxyhalides, $\mathrm{BiOX}(\mathrm{X}=\mathrm{Cl}, \mathrm{Br}$, and $\mathrm{I})$ belonging to the class V-VI-VII ternary oxide semiconductors offer substantial photocatalytic applications in the decontamination of toxic pollutants $[16,17]$. The BiOX possesses a particular layered geometry containing $\left[\mathrm{Bi}_{2} \mathrm{O}_{2}\right]^{2+}$ slabs interleaved by double slabs of Iodine atoms that promotes the separation efficacy of photoinduced charges [18]. Moreover, out of the BiOX group members, BiOI has the lowest bang gap (1.7-1.9 eV), thus time taken for photogeneration of induced charges is relatively low in comparison to other group members. However, high recombining tendency of photoinduced charges is still a matter of concern for BiOI. Therefore, it has been functionalized with various materials such as, $\mathrm{TiO}_{2[19]}, \mathrm{BiVO}_{4[20]}, \mathrm{BiPO}_{4}$ [21], $\mathrm{WO}_{3}$ [22], $\mathrm{Bi}_{2} \mathrm{~S}_{3}$ [23], carbon quantum dots [24], and $\mathrm{CdS}[25]$ etc.

Modification of semiconductors with noble metal offers a remarkable way of improving the photocatalytic efficacy of a material. It is well-established that the associating noble metal with a semiconductor facilitates the trapping of the photoinduced electrons, leading to high separating tendency of the photoinduced charges $[26,27]$. Among the various noble metals such as, $\mathrm{Au}, \mathrm{Rh}$, $\mathrm{Pd}$, Pt, etc., Ag is considered as a suitable dopant for numerous semiconductors owing to its economic viability, minimal toxicity and high antibacterial action. Therefore, the coupling of Ag with BiOI can effectively boost the decontamination of the pollutants along with antibacterial action. Recently, Lin et al.[28] coupled Ag with BiOI and found that Ag/BiOI disintegrated higher rhodamine $\mathrm{B}(\mathrm{RhB})$ than the pristine BiOI. In another study, Liu et al. [29] have reported a series of $\mathrm{Ag} / \mathrm{BiOI}$ composites with varying $\mathrm{Ag}$ amounts, and it was obtained that the $0.6 \% \mathrm{Ag} / \mathrm{BiOI}$ showed the highest photocatalytic efficacy towards the disintegration of acid orange II, MO and RhB. Similarly, Zhong et al. [30] have also reported the Ag/BiOI composite with superior photodisintegration efficacy towards RhB.

Considering the aforementioned and certain other reports on $\mathrm{BiOI}$ and $\mathrm{Ag} / \mathrm{BiOI}$ composites, few conclusions can be drawn i.e. the synthesis method which involves a reducing or stabilizing agent tends to produce BiOI with 3D hierarchical structures [28, 29]; in contrast, without the use of any reducing or stabilizing agent, a nanoplate-like structure of BiOI was observed [31,32]. Our study aims to utilized a flavonoid constituent i.e. quercetin in the synthesis process as a natural stabilizing agent to eliminate the chemical stabilizers and solvents that may 
inflict secondary pollution. Quercetin occurs naturally in many plants such as Azadirachta indica, Ocimum sanctum, Saraca indica, tomato, caper, blackberry, onion, etc. [33]. It possesses antioxidant and stabilizing characteristics due to the presence of phenolic and ketonic groups in the structure, which can readily form chelates with the metals ions [34]. Motivating by these facts, we have synthesized quercetin-mediated $\mathrm{BiOI}$ and $\mathrm{BiOI}-\mathrm{Ag}$ composites, and a detailed mechanism has been discussed regarding the complexation of quercetin with the BiOI-Ag.

\section{Materials and method}

\subsection{Chemicals}

The chemicals i.e. bismuth nitrate pentahydrate $\left(\mathrm{Bi}\left(\mathrm{NO}_{3}\right)_{3} .5 \mathrm{H}_{2} \mathrm{O}\right)$, silver nitrate $\left(\mathrm{AgNO}_{3}\right)$, potassium iodide (KI), methyl orange (MO) were procured from Merck India. quercetin?

\subsection{Synthesis of BiOI and BiOI-Ag}

A stock solution of quercetin was obtained by dissolving a yellow coloured quercetin powder in $10 \mathrm{~mL}$ mixture [water/ethanol (v/v ratio)] and a $0.1 \mathrm{M}$ solution was prepared. To synthesize $\mathrm{BiOI}$, a $0.05 \mathrm{M}$ solution of $\mathrm{Bi}\left(\mathrm{NO}_{3}\right)_{3} .5 \mathrm{H}_{2} \mathrm{O}$ was prepared and added dropwise to the $0.1 \mathrm{M}$ quercetin solution under magnetic stirring. Thereafter, a $0.05 \mathrm{M}$ solution of KI was added dropwise to the above slurry under vigorous stirring at room temperature, with subsequent heating at $60^{\circ} \mathrm{C}$ in an oven for $1 \mathrm{~h}$. The precipitated material was separated via centrifugation and it was washed several times with ethanol and double distilled water to decontaminate the sample. Finally, the products were dried overnight at $60^{\circ} \mathrm{C}$.

For the synthesis of BiOI-Ag, a photoreduction method was used. $500 \mathrm{mg}$ of as-prepared $\mathrm{BiOI}$ was dispersed in $30 \mathrm{~mL}$ quercetin solution. Then, a $100 \mathrm{~mL}$ of $\mathrm{AgNO}_{3}$ solution with varying molar concentrations i.e. $0.001 \mathrm{M}, 0.002 \mathrm{M}$ and $0.003 \mathrm{M}$ was added to the BiOI suspension and stirred in the dark for $1 \mathrm{~h}$. Later, the obtained suspension was irradiatd under $40 \mathrm{~W} \mathrm{UV} \mathrm{lamp} \mathrm{for}$ $3 \mathrm{~h}$ with vigorous stirring. Finally, the BiOI-Ag samples was filtered, washed and dried at $60^{\circ} \mathrm{C}$ overnight. The obtained samples were labelled as BiOI-Ag(1), BiOI-Ag(2), and BiOI-Ag(3), respectively.

\subsection{Valuation of photocatalytic effectiveness}


The photocatalytic efficacy of the BiOI, BiOI-Ag(1), BiOI-Ag(2) and BiOI-Ag(3) samples was judged via photo-disintegration of MO. Concisely: $100 \mathrm{mg}$ of the photocatalyst was added to a $100 \mathrm{~mL}$ MO solution $\left(20 \mathrm{mg} \mathrm{L}^{-1}\right)$ in a $250 \mathrm{~mL}$ beaker. Formerly, the slurry was agitated in the dark conditions for certain time intervals i.e. $30 \mathrm{~min}, 60 \mathrm{~min}$ and $90 \mathrm{~min}$ to establish an adsorptiondesorption equilibrium. Then, the visible light source [Four compact fluorescent lamps $(4 \times 28 \mathrm{~W})$ ] was illuminated on the setup under constant stirring and a $50 \mathrm{~g} \mathrm{~L}^{-1} \mathrm{NaNO}_{2}$ solution was employed as a UV cut-off filter. At precise time intervals, $3 \mathrm{~mL}$ of the sample was withdrawn from the beaker, and the absorbance of the sample was analyzed at $465 \mathrm{~nm}$. Similar conditions were applied in testing antibacterial activity against $S$. aureus, $P$. burmani, pseuodomonas, and $P$, aurgesa.

Characterization techniques???

\section{Results and discussion}

\subsection{Characteristics of BiOI, BiOI-Ag(1), BiOI-Ag(2), and BiOI-Ag(3) samples}

The crystal structure and phase composition of the BiOI, BiOI-Ag(1), BiOI-Ag(2), and BiOI-Ag(3) samples were scrutinized via XRD. All the identified peaks corresponding to (002), (102), (110), (112), (004), (200), (114), (212), and (106) planes [Fig. 1(a)] are in accord with JCPDS card No. 73-2062 [35] and signifying the tetragonal phase of BiOI. In addition, the use of quercetin as stabilizer for $\mathrm{BiOI}$ resulted in slight degradation of crystallinity, which could be due crystal defects generation in the lattice that created a charge imbalance and reformed stoichiometry of the $\mathrm{BiOI}$ and $\mathrm{BiOI}-\mathrm{Ag}$ samples. Moreover, no diffraction peaks of $\mathrm{Ag}$ species can be observed in the $\mathrm{Ag}$-doped samples i.e. BiOI-Ag(1), BiOI-Ag(2), and BiOI-Ag(3), which can be attributed to the smaller concentrations of $\mathrm{Ag}(0.001 \mathrm{M}$ to $0.003 \mathrm{M})$. 

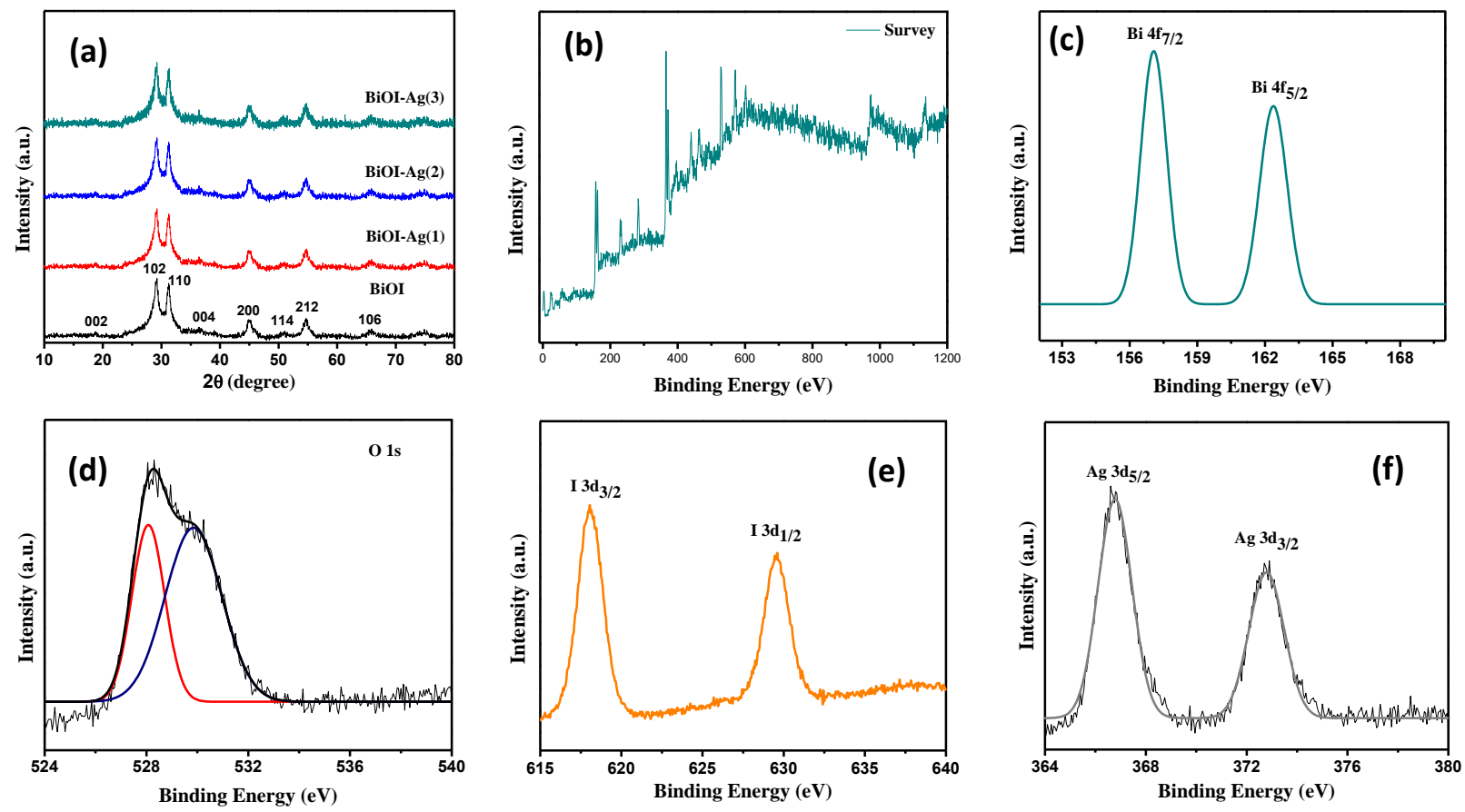

Fig. 1. XRD patterns of BiOI, BiOI-Ag(1), BiOI-Ag(2), and BiOI-Ag(3). XPS spectra of BiOIAg(2) sample: (b) survey, (c) Bi 4f, (d) O 1s, (e) I 3d, and (f) Ag 3d.

The chemical configuration and surface chemical states of BiOI-Ag(2) sample were scrutinized by XPS. [Fig. 1(b)], BiOI-Ag(2) comprised of Bi, O, I, and Ag elements. [Fig. 1(c)], the peaks originating at $156.1 \mathrm{eV}$ and $165.8 \mathrm{eV}$ binding energies to $\mathrm{Bi} 4 \mathrm{f}_{7 / 2}$ and $\mathrm{Bi} 4 \mathrm{f}_{5 / 2}$, which shows $\mathrm{Bi}^{3+}$ in the $\mathrm{BiOI}$ samples. The $\mathrm{O} 1 \mathrm{~s}$ profile showed two identical peaks positioned at 527.7 $\mathrm{eV}$ and $528.4 \mathrm{eV}$, signifying two individual $\mathrm{O}$ species in the sample. The $\mathrm{O} 1 \mathrm{~s}$ peak originated at $529.4 \mathrm{eV}$ and $530.4 \mathrm{eV}$ were ascribed to crystal lattice $\mathrm{O}$ atoms of the $\mathrm{Bi}-\mathrm{O}$ bonds in the $\left[\mathrm{Bi}_{2} \mathrm{O}_{2}\right]$ slabs of $\mathrm{BiOI}$, and the abundant surface oxygen due to the presence of quercetin containing oxygen rich groups in the structure. In the XPS spectrum of I 3d [Fig. 1(f)], the two distinguished peaks at $618.09 \mathrm{eV}$ and $630.12 \mathrm{eV}$ accounts for the binding energies of $\mathrm{I} 3 \mathrm{~d}_{5 / 2}$ and $\mathrm{I} 3 \mathrm{~d}_{3 / 2}$, confirming the presence of $\mathrm{I}^{-}$in BiOI-Ag(2) sample. The peaks identified at $368.1 \mathrm{eV}$ and $374.3 \mathrm{eV}$ [Fig. 1(f)] were attributed to the $\mathrm{Ag} 3 \mathrm{~d}_{5 / 2}$ and $\mathrm{Ag} 3 \mathrm{~d}_{3 / 2}$, respectively. Hence, the results established the existence of $\mathrm{Bi}, \mathrm{O}, \mathrm{I}$ and $\mathrm{AG}$ elements $\mathrm{BiOI}-\mathrm{Ag}(2)$ structure and the $\mathrm{Ag}$ species mainly existed in the Ag (zero) state which were heterogeneously dispersed on the nanoplates of the $3 \mathrm{~d}$ hierarchical BiOI nanoflowers. 

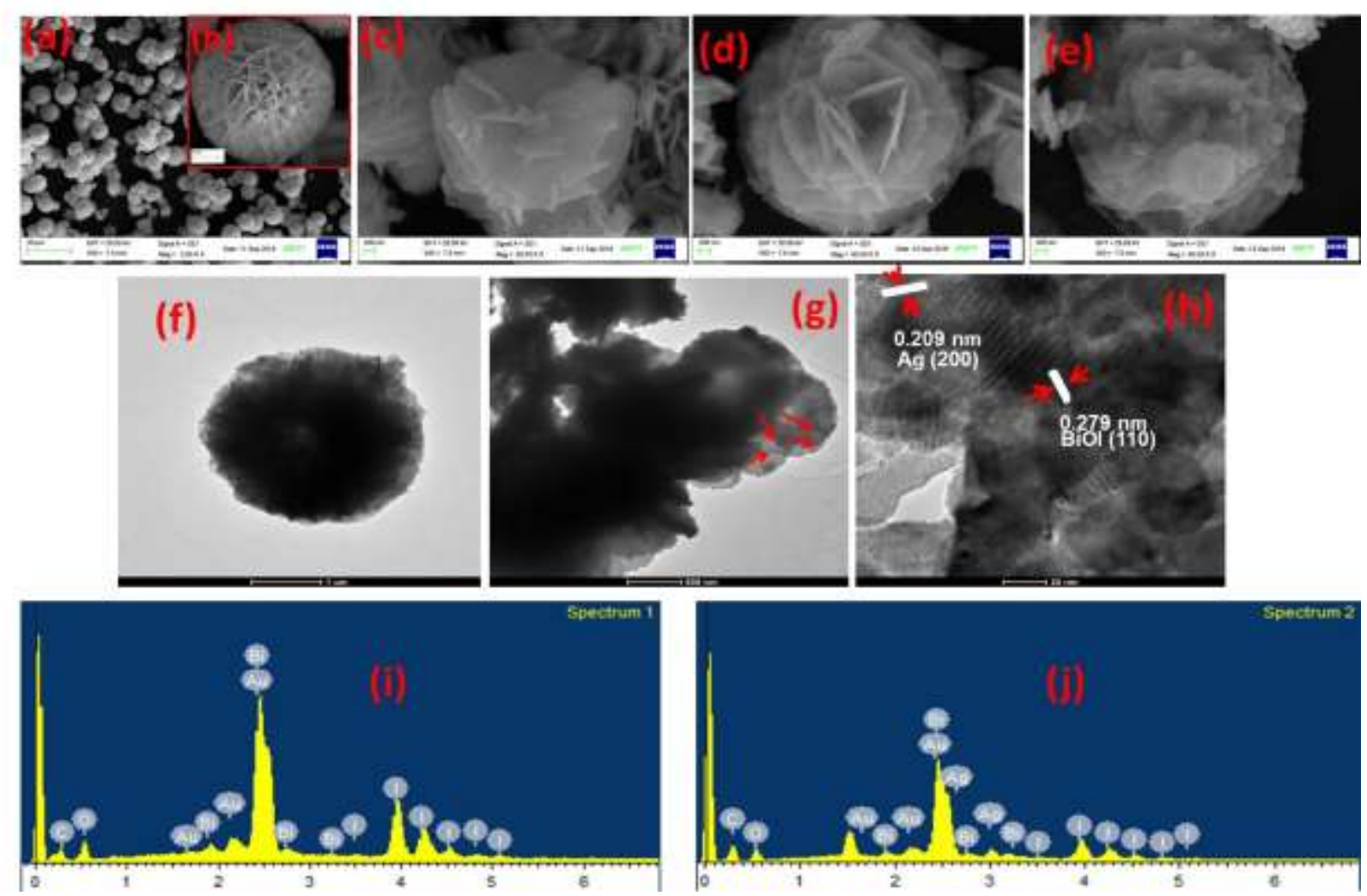

Fig. 2. SEM images of (a, b) BiOI (c) BiOI-Ag(1), (d) BiOI-Ag(2), (e) BiOI-Ag(3). EDAX images of (f) BiOI, and (g) BiOI-Ag(2). TEM and HRTEM images of (h) BiOI and (i) BiOI-Ag(2)

The morphologies of the as-prepared BiOI, BiOI- $\mathrm{Ag}(1), \mathrm{BiOI}-\mathrm{Ag}(2)$, and $\mathrm{BiOI}-\mathrm{Ag}(3)$ samples were analyzed using SEM. As shown in Fig. 2(a), pure BiOI comprised of a uniform 3D nanoflower-like structure with particle size varying from $5 \mu \mathrm{m}$ to $10 \mu \mathrm{m}$, respectively. On higher magnification [Fig. 2(b)], it can be observed that the nanoplates appeared to be interwoven with the neighboring plates to form a dense hierarchical 3D porous structure. In addition, the doping of $\mathrm{Ag}$ in BiOI through photoreduction approach didn't much affect the morphology. Observably, the $\mathrm{Ag}$ nanoparticles were loaded in the 3D matrix of pure $\mathrm{BiOI}$ and became more profound with the increasing doping concentration [Fig. 2(c-e)]. In addition, the TEM images [Fig. 2(f and g)] further confirmed the 3D nanoplate-like structure of $\mathrm{BiOI}$ and the Ag nanoparticles seemed to be well dispersed on the surface of the nanoplates of BiOI. Furthermore, the HRTEM images present that the lattice fringes with $\mathrm{d}$ spacing of $0.279 \mathrm{~nm}$ corresponded to the (110) crystal plane of BiOI whereas that of $0.209 \mathrm{~nm}$ could be indexed to the (200) plane of metallic Ag [(Fig. 2(h)], indicating that $\mathrm{Ag} / \mathrm{BiOI}$ heterojunction was formed. $\mathrm{EDAX}$ analysis of $\mathrm{BiOI}$ and $\mathrm{BiOI}-\mathrm{Ag}(2)$ samples shows 
that the samples were composed of Bi, O, I and Ag atoms [(Fig. 2(i and j)]. The excess oxygen might arise from the incorporation of quercetin in the matrix of BiOI, which contains oxygen rich functional groups such as phenolic and carbonyl groups.
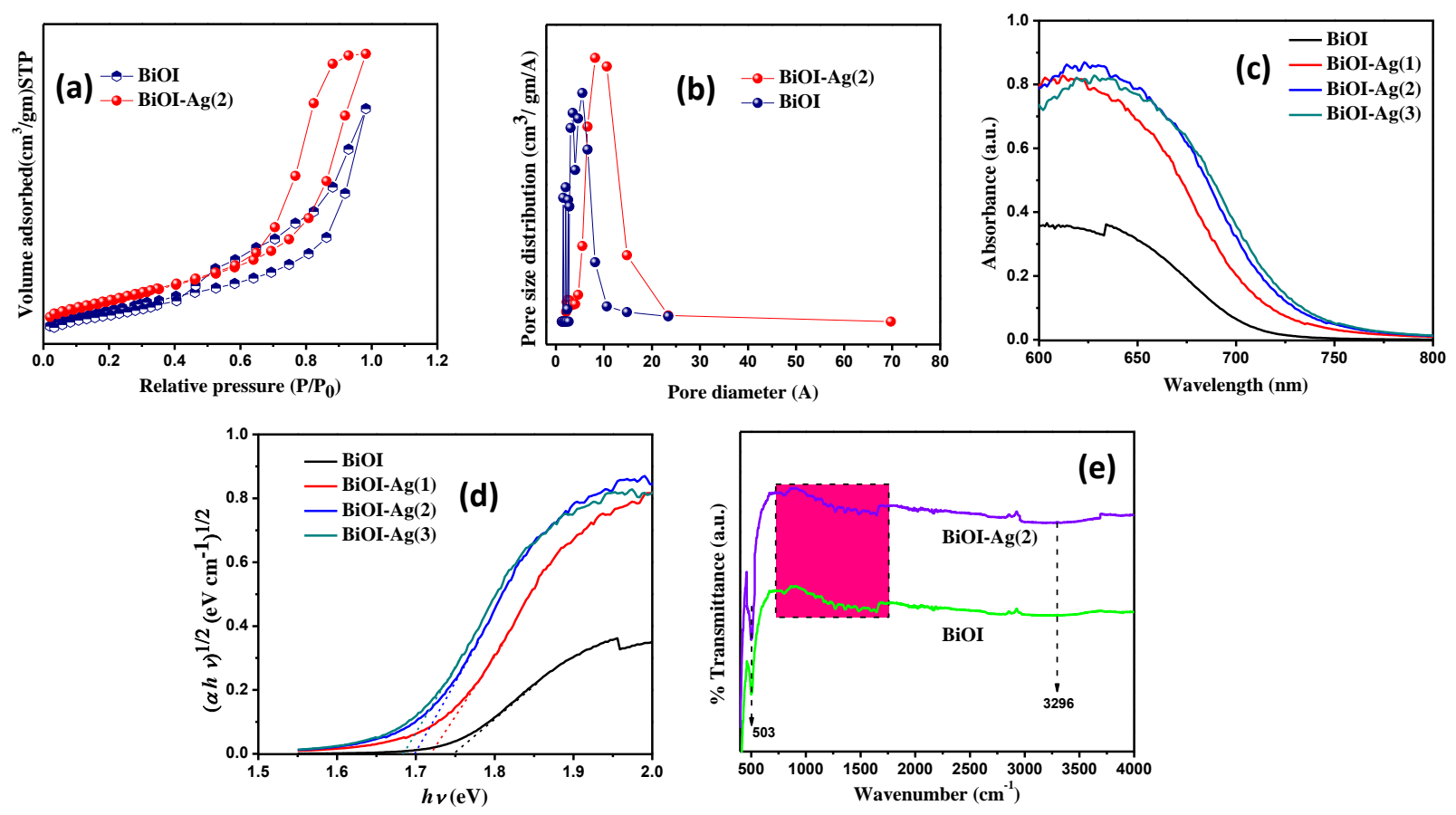

Fig. 3. (a) nitrogen adsorption/desorption, (b) pore of BiOI and BiOI-Ag(2) samples; (c, d) UVVis DRS and Plot of $(\alpha h v)^{n} \mathrm{v} / \mathrm{s}$ hv of BiOI and BiOI-Ag composites (e) IR is missing!!!

The specific surface areas and porosity in the structure of the BiOI and BiOI-Ag(2) samples were inspected via BET isotherms. As shown in Fig. 3a, the BET for both the samples were found to be almost similar with hysteresis loops at relative pressures $(\mathrm{P} / \mathrm{P} 0)$ close to unity, signifying the existence of large mesopores that can be classified as type IV with H3 hysteresis loop. Due to the regular, the hierarchical arrangement and aggregation of the nanoplates a slit-like highly pores structure was formed, which accounted for a wide pore size distribution ranging from $2 \mathrm{~nm}$ to 30 $\mathrm{nm}$, further confirming the existence of mesopores. Furthermore, data in Table 1 indicates that the BiOI-Ag(2) sample possessed slightly higher specific surface areas than the pristine BiOI, which can be attributed to the Ag nanoparticles that were firmly attached on the BiOI nanoflowers and possessed certainly high specific surface area. Hence, it would be reasonable to conclude that there is a crucial role of Ag nanoparticles in enhancing the specific surface area that could be favorable for improving the photocatalytic performances of the BiOI-Ag samples studied. The study of band 
structure and optical property of a semiconductor photocatalyst holds a key importance in influencing the photocatalytic performance. The UV-vis diffuse reflectance spectra of the asprepared samples are displayed in Fig. 4(a), which revealed that the BiOI-Ag composites in comparison to BiOI showed an enhanced absorption and an apparent red-shift in the band gap transition. Among them, the value of $\mathrm{n}$ for $\mathrm{BiOI}$ and $\mathrm{BiOI}-\mathrm{Ag}$ composites is 4 for the indirect transition [29]; subsequently, the band gap energy of the samples were determined by plotting $(\alpha h v)^{1 / 2}$ versus photon energy $(h v)$. As shown in Fig. 5b, the intercept of the tangent to the $\mathrm{X}$ axis provided an approximate analysis of the band gap energy and the calculated band gap energies of the samples are summarized in Table 1. The BiOI sample displayed a band gap of $1.75 \mathrm{eV}$, which is slightly lower than most of the studies reported on BiOI [ref???]. The reason for lowering of band gap of BiOI can be attributed to the quercetin, which we have also reported in our previous paper [34], mainly the quercetin comprises of hydroxyl and carbonyl groups that interacts with the central metal ion in $\mathrm{BiOI}$ i.e. $\mathrm{Bi}^{3+}$ and forms a chelate, resulting into lowering of band gap [36]. In addition, the band gap values of BiOI-Ag composites range from $1.72 \mathrm{eV}$ to $1.65 \mathrm{eV}$ with the increasing $\mathrm{Ag}$ content in BiOI $(0.001 \mathrm{M}$ to $0.003 \mathrm{M})$. This shift in the band gap towards the narrower region can be attributed to the chemical interaction between BiOI and Ag. Hence, the narrower band gap of the BiOI-Ag composites signifies the enhanced efficiency to absorb the incident light which is favorable for the photocatalytic performance. The FTIR spectra of the asprepared $\mathrm{BiOI}$ and $\mathrm{BiOI}-\mathrm{Ag}(2)$ samples was recorded $\left(400-4000 \mathrm{~cm}^{-1}\right.$ range) to scrutinize the functional groups accountable for higher absorption of the incident light. In the spectra of the samples [Fig. 4(g)], a wide band originated at $3296 \mathrm{~cm}^{-1}$ can be assigned to the $-\mathrm{OH}$ stretching mode of water, meanwhile; the peak at $503 \mathrm{~cm}^{-1}$ was ascribed to the stretching vibrations of the Bi-O bond [37],[38]. Interestingly, many distinctive peaks were witnessed and highlighted in the pink region. The strong bands occurring in the range of $1730-1740 \mathrm{~cm}^{-1}$ are recognized as the carbonyl group $(\mathrm{C}=\mathrm{O})$ vibrations. The infrared absorption and stretching mode of the alkene group $(\mathrm{C}=\mathrm{C})$ covered a wide range from $1489-1715 \mathrm{~cm}^{-1}$. In addition, the peaks occurring at $1053 \mathrm{~cm}^{-1}$, $1296 \mathrm{~cm}^{-1}, 1376 \mathrm{~cm}^{-1}$ and $1487 \mathrm{~cm}^{-1}$ are credited to the ester linkage, asymmetric-CH deformation mode of alkyl group $\left(-\mathrm{CH}_{3}\right)$ and phenolic stretching mode of the $-\mathrm{OH}$ group. Therefore, the wide range of peaks confirms the incorporation of quercetin in the BiOI and BiOI-Ag samples that is vital for absorption of incident light to produce the photoinduced charges [39-41].

Table1: Parameters of as-prepared samples 


\begin{tabular}{|c|c|c|c|c|}
\hline Sample & $S_{\text {BET }}\left(m^{2} g^{-1}\right)$ & $\begin{array}{c}\text { Average pore } \\
\text { size (nm) }\end{array}$ & $\begin{array}{c}\text { Pore volume } \\
\left(\mathrm{cm}^{3} \mathbf{g}^{-1}\right)\end{array}$ & $\begin{array}{c}\text { Band Gap } E_{g} \\
(\mathrm{eV})\end{array}$ \\
\hline $\mathrm{BiOI}$ & 72 & 8.2 & 0.25 & 1.75 \\
\hline $\mathrm{BiOI}-\mathrm{Ag}(1)$ & - & - & - & 1.72 \\
\hline BiOI-Ag(2) & - & - & - & 1.69 \\
\hline BiOI-Ag(3) & 83 & 5.8 & 0.14 & 1.65 \\
\hline
\end{tabular}

\subsection{Photocatalytic activity}

The photocatalytic efficacy of BiOI, BiOI-Ag(1), BiOI-Ag(2), and BiOI-Ag(3) samples, disintegration of a typical organic pollutant $\mathrm{MO}$ was selected as the photoreaction probe. The blank test signified that the MO is stable and cannot be disintegrated without the photocatalyst. In addition, the adsorption study was conducted in the dark for different time intervals i.e. $20 \mathrm{~min}$, $40 \mathrm{~min}$, and $60 \mathrm{~min}$ to ensure adequate interaction between the samples and the MO solution. As shown in Fig. 7, a large percentage of MO i.e. $36 \%, 41 \%, 45 \%$, and $47 \%$ was adsorbed on the corresponding BiOI, BiOI-Ag(1), BiOI-Ag(2), and BiOI-Ag(3) samples. In comparison to our previous report on $\mathrm{BiOI}$ i.e. $\mathrm{BiOI}-\mathrm{C}$ (without quercetin), the quercetin-mediated $\mathrm{BiOI}$ in the present study showed much enhanced photocatalytic performance and degraded $91 \%$ of MO, which is almost 20 times higher than that of BiOI-C, the probable reason for the increase in the photocatalytic performance has been discussed in the latter sections. Moreover, the photocatalytic activities of BiOI-Ag composites were further enhanced and the $\mathrm{MO}$ over corresponding $\mathrm{BiOI}-\mathrm{Ag}$ samples reached 97-100 \%. The results suggested that Ag content in the BiOI-Ag composites improved photocatalytic efficacy. The smaller Ag content $(0.001 \mathrm{M})$ in BiOI improved the $\mathrm{MO}$ disintegration from $91 \%$ to $97 \%$, and complete disintegration of MO was achieved on further increasing the $\mathrm{Ag}$ content $(0.002 \mathrm{M})$. However, the photocatalytic performance reduced when the $\mathrm{Ag}$ amount rose to $0.003 \mathrm{M}$, which can be due to the excessive trapping sites initiated by the increased doping concentration of $\mathrm{Ag}$ that assisted the recombination of photoinduced charges. According to the results obtained from the photocatalytic performances, the optimized doping concentration of $\mathrm{Ag}$ in the BiOI- $\mathrm{Ag}$ composites was $0.002 \mathrm{M}$. The rate constants evaluated from the data plotted and are shown in Fig. 7. The rate constant for BiOI- $\mathrm{Ag}(2)$ to remove MO is 2.3952 $\mathrm{min}^{-1}$, which is $\sim 3.19$ times as large as that of $\mathrm{BiOI}\left(0.7497 \mathrm{~min}^{-1}\right)$. 

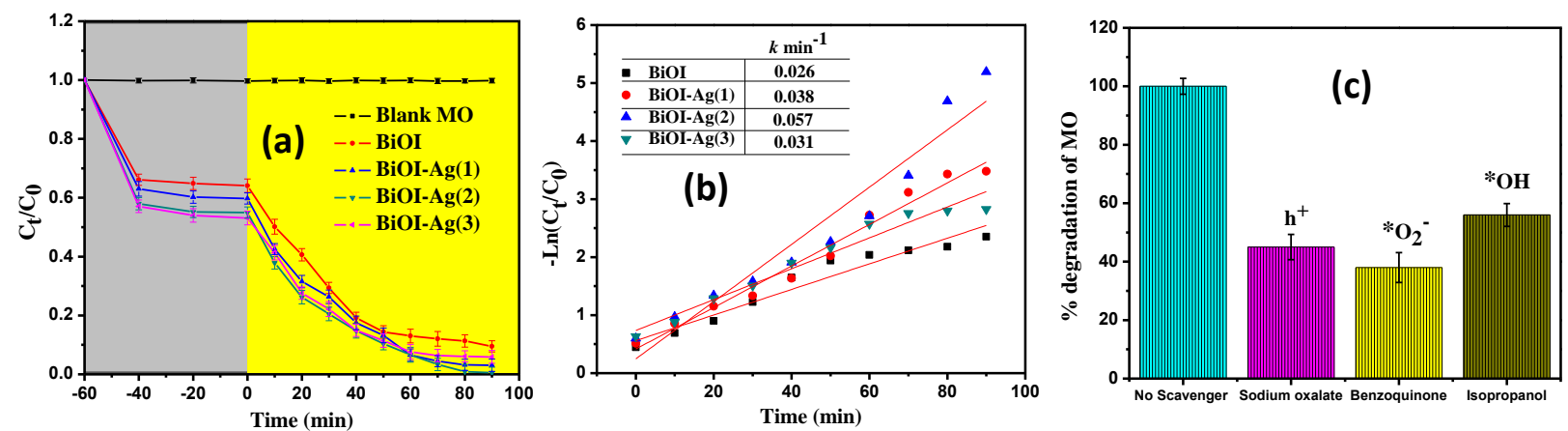

(d)

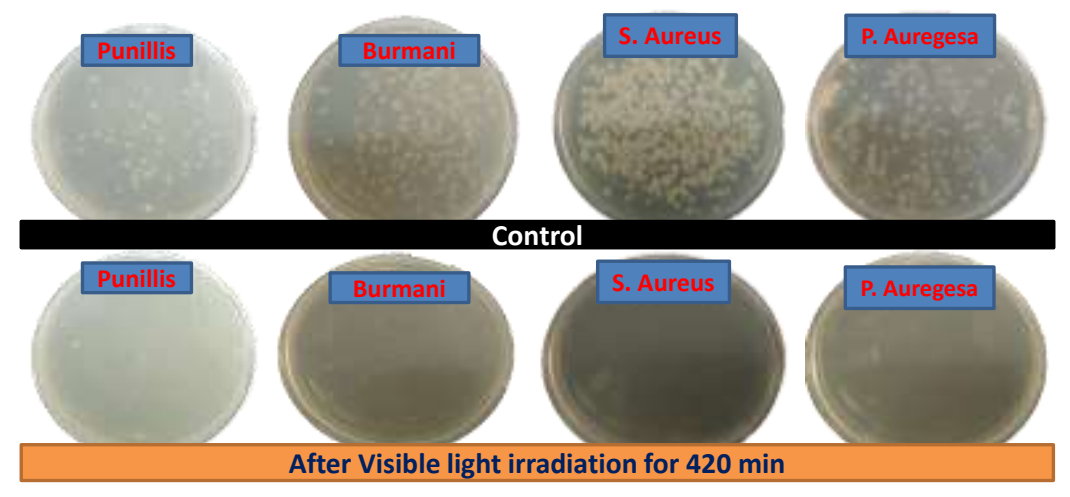

Fig. 5. (a) Photodisintegration of $\mathrm{MO}$ by $\mathrm{BiOI}$ and $\mathrm{BiOI}-\mathrm{Ag}$ composites (b) kinetic linear simulation curves and pseudo first-order kinetic rate constants $k$ for MO degradation over the samples, (c) Photodisintegration of MO by BiOI-Ag(2) in the presence of different scavengers, (d) Images of bacterial colonies formed by mycropoppus lylae, S. aureus, P. burmani, pseuodomonas, and $P$, aurgesa cells treated by as-optimized BiOI-Ag(2) composite after $7 \mathrm{~h}$ irradation (concentration of catalysts: $1 \mathrm{~g} \mathrm{~L}^{-1}$ ).

Moreover, the Fig. 6b, represents the photos of colonies formed after treatment. When being irradiated, results show that $\mathrm{BiOCl}-\mathrm{Ag}$ could strongly suppress the growth and reproduction of both bacteria. As a result, no colony was found. Such excellent antibacterial efficiency may be due to both the photocatalytic effect and antibacterial effect of Ag NPs.

\subsection{Photocatalytic Mechanism}

The photocatalytic efficacy of a photocatalyst is mainly gravitated on the effectual separation of the photoinduced charges, hence; the rapid and even responses to each ON/OFF light intervals signifies an effectual reproducibility of the equivalent samples. As shown in Fig. 6(a), an insignificant difference between the photocurrent intensities of the $\mathrm{BiOI}$ and $\mathrm{BiOI}-\mathrm{Ag}(2)$ samples 
can be observed, which could well be attributed to the complex formation between the functional groups of quercetin and the $\mathrm{Bi}^{3+}$ ion of the pristine $\mathrm{BiOI}$. Meanwhile, the coupling of $\mathrm{Ag}$ with the quercetin-mediated $\mathrm{BiOI}$ resulted in the formation of heterojunctions among the $\mathrm{BiOI}, \mathrm{Ag}$ and the quercetin molecule, due to which the BiOI-Ag(2) sample displayed an elevated photocurrent intensity than that of BiOI. The prolonged lifetime of the photoinduced charges can further be confirmed with the EIS and PL study [Fig. 6(b and c)], which can be utilized to understand the charge transfer mechanism in the BiOI- $\mathrm{Ag}(2)$ sample.
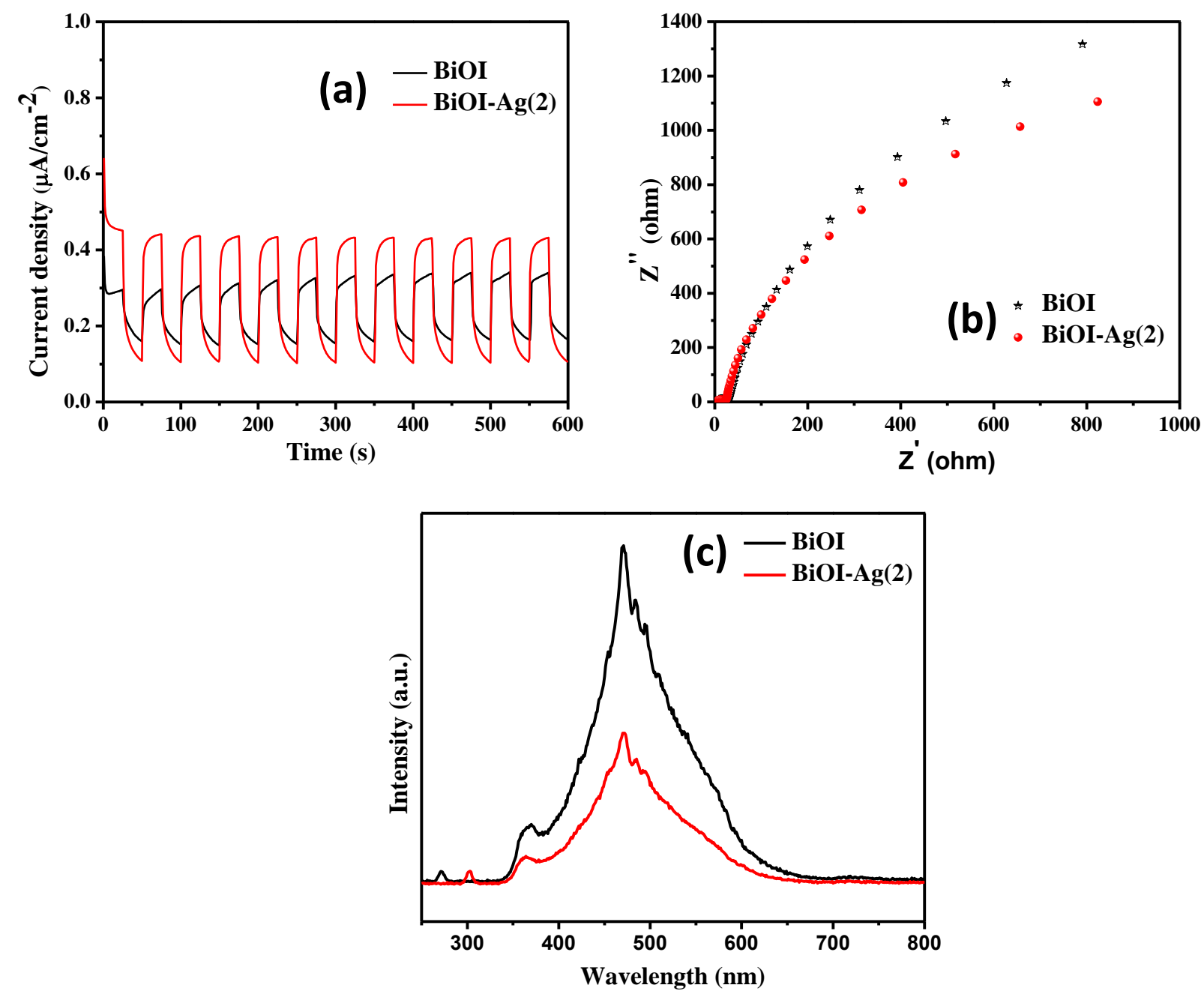

Fig. 6. (a) Photocurrent response, (b) EIS, (c) PL spectra of BiOI and BiOI-Ag(2).

In our previous study [34], we have successfully shown the role of quercetin as a potential stabilizer and sensitizer as it possesses an electron-accepting nature, which allows the high absorption of the incident light for the massive production of the photoinduced electron-hole pairs. 
The quercetin molecule shows higher energy levels than that of BiOI and $\mathrm{I}^{-} / \mathrm{I}^{3-}$ redox couple electrolyte $(4.75 \mathrm{~V})$ that sufficiently facilitated the charge migration and regeneration of the photoinduced charges. Meanwhile, due to higher Fermi level the BiOI could easily transfer the electrons to the $\mathrm{Ag}$ metal, resulting in the formation of heterojunctions among quercetin, $\mathrm{BiOI}$ and $\mathrm{Ag}$ that subsequently inhibited the recombining tendency of the photogenerated charges. Therefore, $\mathrm{O}_{2}$ molecules adsorbed on the photocatalyst surface can readily form ${ }^{*} \mathrm{O}_{2}{ }_{2}$, and subsequently, the other active species such as $* \mathrm{OH}$ and $\mathrm{h}^{+}$can also be produced via series of chain reaction. Hence, all the active species formed during the photo-reduction and photo-oxidation step actively participates in the antibacterial activity and degrades MO.

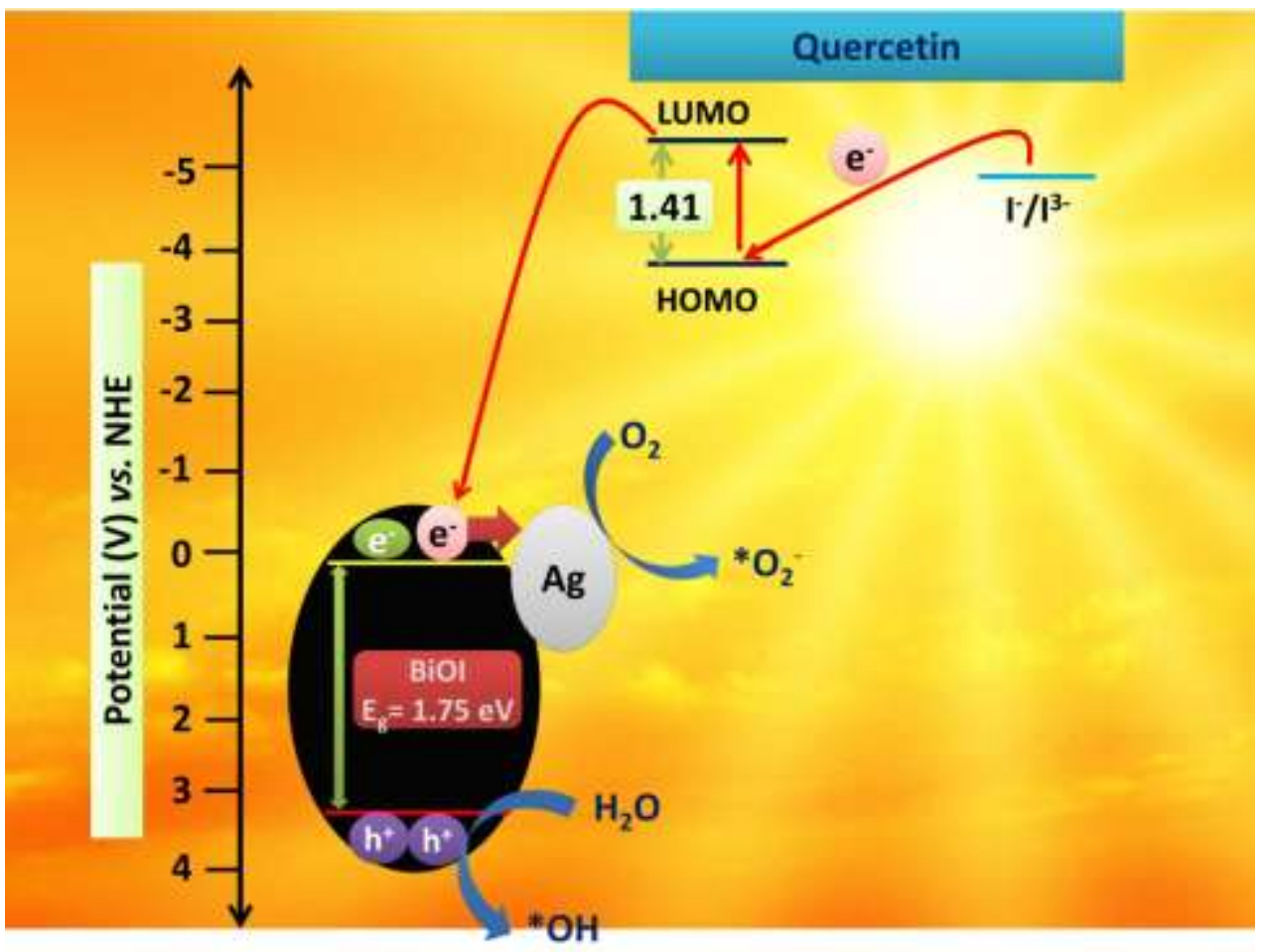

Fig. 7. Photocatalytic degradation mechanism of contaminants with BiOI-Ag(2).

\section{Conclusions}

A novel BiOI-Ag photocatalyst with tremendous photocatalytic efficacy was successfully prepared through quercetin-mediated hydrolysis process followed by a photo-deposited methodology. The quercetin provided 3D nanoflower morphology and also significantly enhanced the solar absorption. In addition, the coupling of $\mathrm{Ag}$ with $\mathrm{BiOI}$ further resulted in the substantial progress 
in the antibacterial action towards four different bacteria and complete MO disintegration under visible light exposure. The heterojunctions formed among the quercetin molecule, $\mathrm{BiOI}$ and $\mathrm{Ag}$ successfully inhibited the recombining ability of the photogenerated charges and prolonged the charge transfer process, thereby stimulating the photocatalytic efficacy. Hence, it can be speculated that the as-optimized quercetin-assisted BiOI-Ag photocatalysts holds great potential for environmental remediation.

\section{Acknowledgment}

This work is financially supported by DST, Government of India (INT/HUN/P-06/2016), NRDIO, Hungary (TÉT_15-IN-1-2016-0013).

\section{References}

[1] A. Fujishima, K. Honda, Electrochemical photolysis of water at a semiconductor electrode, Nature, 238 (1972) 37-38.

[2] Z. Zou, J. Ye, K. Sayama, H. Arakawa, Direct splitting of water under visible light irradiation with an oxide semiconductor photocatalyst, Nature, 414 (2001) 625-627.

[3] Z. Dong, M. Wu, J. Wu, Y. Ma, Z. Ma, In situ synthesis of TiO 2/SnO x-Au ternary heterostructures effectively promoting visible-light photocatalysis, Dalton Transactions, 44 (2015) 11901-11910.

[4] X. Chen, S.S. Mao, Titanium dioxide nanomaterials: synthesis, properties, modifications, and applications, Chem. Rev., 107 (2007) 2891-2959.

[5] W.-T. Sun, Y. Yu, H.-Y. Pan, X.-F. Gao, Q. Chen, L.-M. Peng, CdS quantum dots sensitized TiO2 nanotube-array photoelectrodes, J. Am. Chem. Soc., 130 (2008) 1124-1125.

[6] L. Cao, Y. Qu, D. Xie, C. Jing, Preparation and characterization of porous TiO 2 with La 2 O 3 load, Rare Metals, 30 (2011) 221-224.

[7] T. Morikawa, T. Ohwaki, K.-i. Suzuki, S. Moribe, S. Tero-Kubota, Visible-light-induced photocatalytic oxidation of carboxylic acids and aldehydes over $\mathrm{N}$-doped $\mathrm{TiO} 2$ loaded with Fe, $\mathrm{Cu}$ or Pt, Applied Catalysis B: Environmental, 83 (2008) 56-62.

[8] C. He, X. Li, Y. Xiong, X. Zhu, S. Liu, The enhanced PC and PEC oxidation of formic acid in aqueous solution using a $\mathrm{Cu}-\mathrm{TiO}$ 2/ITO film, Chemosphere, 58 (2005) 381-389. 
[9] K. Dai, T. Peng, H. Chen, J. Liu, L. Zan, Photocatalytic degradation of commercial phoxim over La-doped $\mathrm{TiO} 2$ nanoparticles in aqueous suspension, Environmental science \& technology, 43 (2009) 1540-1545.

[10] L. Liu, Z. Liu, H. Bai, D.D. Sun, Concurrent filtration and solar photocatalytic disinfection/degradation using high-performance $\mathrm{Ag} / \mathrm{TiO} 2$ nanofiber membrane, Water Res., 46 (2012) 1101-1112.

[11] G.K. Parshetti, R.-a. Doong, Synergistic effect of nickel ions on the coupled dechlorination of trichloroethylene and 2, 4-dichlorophenol by Fe/TiO 2 nanocomposites in the presence of UV light under anoxic conditions, Water Res., 45 (2011) 4198-4210.

[12] L. Yang, S. Luo, Y. Li, Y. Xiao, Q. Kang, Q. Cai, High efficient photocatalytic degradation of p-nitrophenol on a unique $\mathrm{Cu} 2 \mathrm{O} / \mathrm{TiO} 2$ pn heterojunction network catalyst, Environmental science \& technology, 44 (2010) 7641-7646.

[13] W. Kim, T. Tachikawa, T. Majima, W. Choi, Photocatalysis of dye-sensitized TiO2 nanoparticles with thin overcoat of $\mathrm{A} 12 \mathrm{O} 3$ : enhanced activity for $\mathrm{H} 2$ production and dechlorination of CCl4, The Journal of Physical Chemistry C, 113 (2009) 10603-10609.

[14] I.C. Maurya, A.K. Gupta, P. Srivastava, L. Bahadur, Natural Dye Extracted From Saraca asoca Flowers as Sensitizer for TiO2-Based Dye-Sensitized Solar Cell, Journal of Solar Energy Engineering, 138 (2016) 051006.

[15] S. Ushiroda, N. Ruzycki, Y. Lu, M. Spitler, B. Parkinson, Dye sensitization of the anatase (101) crystal surface by a series of dicarboxylated thiacyanine dyes, J. Am. Chem. Soc., 127 (2005) 5158-5168.

[16] E. Bárdos, A.K. Király, Z. Pap, L. Baia, S. Garg, K. Hernádi, The effect of the synthesis temperature and duration on the morphology and photocatalytic activity of $\mathrm{BiOX}(\mathrm{X}=\mathrm{Cl}, \mathrm{Br}, \mathrm{I})$ materials, Appl. Surf. Sci., 479 (2019) 745-756.

[17] N. Sharma, Z. Pap, S. Garg, K. Hernádi, Hydrothermal synthesis of $\mathrm{BiOBr}$ and $\mathrm{BiOBr} / \mathrm{CNT}$ composites, their photocatalytic activity and the importance of early Bi6O6 $(\mathrm{OH}) 3(\mathrm{NO} 3) 3 \cdot 1.5$ H2O formation, Appl. Surf. Sci., (2019) 143536.

[18] S. Garg, M. Yadav, A. Chandra, K. Hernadi, A Review on BiOX (X= Cl, Br and I) Nano/Microstructures for Their Photocatalytic Applications, Journal of nanoscience and nanotechnology, 19 (2019) 280-294. 
[19] G. Dai, J. Yu, G. Liu, Synthesis and enhanced visible-light photoelectrocatalytic activity of $\mathrm{p}-\mathrm{n}$ junction BiOI/TiO2 nanotube arrays, The Journal of Physical Chemistry C, 115 (2011) 73397346.

[20] H. Huang, Y. He, X. Du, P.K. Chu, Y. Zhang, A General and Facile Approach to Heterostructured Core/Shell BiVO4/BiOI p-n Junction: Room-Temperature in Situ Assembly and Highly Boosted Visible-Light Photocatalysis, ACS Sustainable Chemistry \& Engineering, 3 (2015) 3262-3273.

[21] Y. Liu, W. Yao, D. Liu, R. Zong, M. Zhang, X. Ma, Y. Zhu, Enhancement of visible light mineralization ability and photocatalytic activity of BiPO 4/BiOI, Applied Catalysis B: Environmental, 163 (2015) 547-553.

[22] Y. Feng, C. Liu, H. Che, J. Chen, K. Huang, C. Huang, W. Shi, The highly improved visible light photocatalytic activity of BiOI through fabricating a novel $\mathrm{p}-\mathrm{n}$ heterojunction BiOI/WO 3 nanocomposite, CrystEngComm, 18 (2016) 1790-1799.

[23] J. Cao, B. Xu, H. Lin, B. Luo, S. Chen, Novel heterostructured Bi 2 S 3/BiOI photocatalyst: facile preparation, characterization and visible light photocatalytic performance, Dalton Transactions, 41 (2012) 11482-11490.

[24] J. Di, J. Xia, M. Ji, L. Xu, S. Yin, Q. Zhang, Z. Chen, H. Li, Carbon quantum dots in situ coupling to bismuth oxyiodide via reactable ionic liquid with enhanced photocatalytic molecular oxygen activation performance, Carbon, 98 (2016) 613-623.

[25] F. Duo, Y. Wang, C. Fan, X. Zhang, Y. Wang, Enhanced visible light photocatalytic activity and stability of CQDs/BiOBr composites: The upconversion effect of CQDs, J. Alloys Compd., 685 (2016) 34-41.

[26] H. Cheng, B. Huang, P. Wang, Z. Wang, Z. Lou, J. Wang, X. Qin, X. Zhang, Y. Dai, In situ ion exchange synthesis of the novel $\mathrm{Ag} / \mathrm{AgBr} / \mathrm{BiOBr}$ hybrid with highly efficient decontamination of pollutants, Chem. Commun., 47 (2011) 7054-7056.

[27] Y. Gao, L. Wang, Z. Li, C. Li, X. Cao, A. Zhou, Q. Hu, Microwave-assisted synthesis of flower-like $\mathrm{Ag}-\mathrm{BiOCl}$ nanocomposite with enhanced visible-light photocatalytic activity, Mater. Lett., 136 (2014) 295-297.

[28] H. Lin, Y. Zhao, Y. Wang, J. Cao, S. Chen, Controllable in-situ synthesis of Ag/BiOI and $\mathrm{Ag} / \mathrm{AgI} / \mathrm{BiOI}$ composites with adjustable visible light photocatalytic performances, Mater. Lett., 132 (2014) 141-144. 
[29] H. Liu, W. Cao, Y. Su, Y. Wang, X. Wang, Synthesis, characterization and photocatalytic performance of novel visible-light-induced Ag/BiOI, Applied Catalysis B: Environmental, 111 (2012) 271-279.

[30] S. Zhong, B. Wang, H. Zhou, C. Li, X. Peng, S. Zhang, Fabrication and characterization of $\mathrm{Ag} / \mathrm{BiOI} / \mathrm{GO}$ composites with enhanced photocatalytic activity, J. Alloys Compd., 806 (2019) 401-409.

[31] H. Cheng, W. Wang, B. Huang, Z. Wang, J. Zhan, X. Qin, X. Zhang, Y. Dai, Tailoring AgI nanoparticles for the assembly of $\mathrm{AgI} / \mathrm{BiOI}$ hierarchical hybrids with size-dependent photocatalytic activities, Journal of Materials Chemistry A, 1 (2013) 7131-7136.

[32] S. Wang, Y. Guan, L. Wang, W. Zhao, H. He, J. Xiao, S. Yang, C. Sun, Fabrication of a novel bifunctional material of $\mathrm{BiOI} / \mathrm{Ag} 3 \mathrm{VO} 4$ with high adsorption-photocatalysis for efficient treatment of dye wastewater, Applied Catalysis B: Environmental, 168 (2015) 448-457.

[33] S. Çakar, M. Özacar, The effect of iron complexes of quercetin on dye-sensitized solar cell efficiency, Journal of Photochemistry and Photobiology A: Chemistry, 346 (2017) 512-522.

[34] M. Yadav, S. Garg, A. Chandra, K. Hernadi, Quercetin-sensitized BiOF nanostructures: An investigation on photoinduced charge transfer and regeneration process for degradation of organic pollutants, Journal of Photochemistry and Photobiology A: Chemistry, (2019) 112014.

[35] X. Xiao, W.-D. Zhang, Facile synthesis of nanostructured BiOI microspheres with high visible light-induced photocatalytic activity, J. Mater. Chem., 20 (2010) 5866-5870.

[36] M. Yadav, S. Garg, A. Chandra, K. Hernadi, Fabrication of leaf extract mediated bismuth oxybromide/oxyiodide (BiOBrxI1-x) photocatalysts with tunable band gap and enhanced optical absorption for degradation of organic pollutants, J. Colloid Interface Sci., (2019).

[37] S.A. Mozaffari, M. Saeidi, R. Rahmanian, Photoelectric characterization of fabricated dyesensitized solar cell using dye extracted from red Siahkooti fruit as natural sensitizer, Spectrochimica Acta Part A: Molecular and Biomolecular Spectroscopy, 142 (2015) 226-231.

[38] G. Cheng, J. Xiong, F.J. Stadler, Facile template-free and fast refluxing synthesis of 3D desertrose-like BiOCl nanoarchitectures with superior photocatalytic activity, New J. Chem., 37 (2013) 3207-3213.

[39] P. Luo, H. Niu, G. Zheng, X. Bai, M. Zhang, W. Wang, From salmon pink to blue natural sensitizers for solar cells: Canna indica L., Salvia splendens, cowberry and Solanum nigrum L, Spectrochimica Acta Part A: Molecular and Biomolecular Spectroscopy, 74 (2009) 936-942. 
[40] C. Li, X. Yang, R. Chen, J. Pan, H. Tian, H. Zhu, X. Wang, A. Hagfeldt, L. Sun, Anthraquinone dyes as photosensitizers for dye-sensitized solar cells, Sol. Energy Mater. Sol. Cells, 91 (2007) 1863-1871.

[41] A. Kyaw, X. Sun, J. Zhao, J. Wang, D. Zhao, X. Wei, X. Liu, H. Demir, T. Wu, Topilluminated dye-sensitized solar cells with a room-temperature-processed $\mathrm{ZnO}$ photoanode on metal substrates and a Pt-coated Ga-doped ZnO counter electrode, J. Phys. D: Appl. Phys., 44 (2011) 045102. 